\title{
Pilot study of phenytoin in rheumatoid arthritis
}

\author{
DIANA G MACFARLANE, BERYL CLARK, AND GABRIEL S PANAYI \\ From the Rheumatology Unit, Lewisham and Guy's Hospitals, clo Lewisham Hospital, Lewisham High \\ Street, London
}

SUMMARY The anticonvulsant drug phenytoin has several interesting immunological properties which could theoretically be of benefit in the treatment of rheumatoid arthritis. For this reason a pilot study has been carried out on 11 patients with active classical or definite disease. Seven patients completed a 20 week course of treatment and showed continuous improvement at 12 and 20 weeks and some deterioration eight weeks after the drug was stopped. Laboratory and clinical measurements of disease activity responded favourably during the treatment period, suggesting that phenytoin may have second line activity.

Key words: second line drug.

Rheumatoid arthritis (RA) is an immunologically mediated disease characterised by erosive destruction of joints. As a consequence, effective forms of therapy often involve the induction of immunosuppression. Phenytoin, one of the hydantoin group of anticonvulsants, has many interesting immunological properties such as production of selective IgA deficiency, ${ }^{1}$ the induction of spontaneous suppressor $\mathrm{T}$ cell activity, and thus antibody deficiency, ${ }^{2}$ and occasional induction of malignant lymphoma in long term users. ${ }^{3}$ It also has properties relevant to the destructive process seen in RA, such as the inhibition of collagenase ${ }^{4}$ and the stimulation of collagen producing fibroblasts in the gums of some epileptics. ${ }^{5}$ Clinical experience has also suggested a protective role for phenytoin since epileptics on this anticonvulsant have been noticed to have less severe RA. ${ }^{6}$

For these reasons a pilot study of phenytoin in RA has been carried out.

\section{Patients and methods}

PAT I E N TS

Eleven patients with definite or classical RA were included who had early morning stiffness (EMS) $>45$ minutes, erythrocyte sedimentation rate (ESR) $>30 \mathrm{~mm} / 1 \mathrm{st} \mathrm{h}$, five or more painful or swollen joints, and had not received another second line drug for four months or longer before entry into the

Accepted for publication 2 May 1986.

Correspondence to Dr Diana G Macfarlane, Rheumatology Unit, Lewisham Hospital, Lewisham High Street, London SE13 6LH. study. There were three male and eight female participants, with a mean age of 56.8 years (range 35-72 years) and a mean disease duration of 12.4 years (range 1-26 years). Ten were positive fot rheumatoid factor (IgM RF).

TREATMENT PROTOCOL

Phenytoin was given daily as follows: week 1100 $\mathrm{mg}$, week $2200 \mathrm{mg}$, weeks 3-18300 mg, week 19200 $\mathrm{mg}$, week $20100 \mathrm{mg}$, and then stopped. The reason for this slow introduction and withdrawal was avoidance of central nervous system side effects. Patients were allowed to continue their nonsteroidal anti-inflammatory drugs, and one patient continued on $5 \mathrm{mg}$ of prednisolone. Patients who deteriorated when not receiving phenytoin were transferred to an alternative second line drug.

\section{A S S E S S M E N T S}

The following clinical measurements were made on day 0 and at four-weekly intervals: $10 \mathrm{~cm}$ visual analogue scale (VAS) for pain, duration of early morning stiffness (EMS) in minutes, and Ritchie articular index (RI). The non-leading question, 'Have the tablets upset you in any way?', was used to assess side effects. The following laboratory measurements were performed: full blood count, ESR, $C$ reactive protein (CRP) by enzyme linked immunosorbent assay (ELISA), IgM RF by ELISA, immunoglobulins $\operatorname{IgG}$, IgA, and IgM, liver function tests, and phenytoin levels.

Full statistical evaluation was made at $0,12,20$, and 28 weeks by Wilcoxon's matched pairs signed 
rank test looking for change compared with 0 weeks (baseline). During the period 20-28 weeks the patients were not receiving phenytoin and were acting as their own controls.

\section{Results}

Nine patients $(82 \%)$ completed 16 weeks of the study and seven completed the entire 28 weeks. Two were withdrawn with intercurrent illness (knee joint replacement and perforated duodenal ulcer) and two developed a mild rash (in reirospect, these two could probably have continued). Seven patients tolerated $300 \mathrm{mg}$ of phenytoin daily, and four patients were maintained on between 100 and 200 mg daily. Phenytoin was detected in the serum of all patients except on two isolated occasions in two different patients, signifying compliance, but levels were lower than expected-owing to either poor absorption or interference by non-steroidal antiinflammatory drugs. The mean phenytoin level was $6.4 \mathrm{mg} / \mathrm{l}$ with a range of $0-16 \mathrm{mg} / \mathrm{l}$. (The therapeutic range for control of epilepsy is $7-20 \mathrm{mg} / \mathrm{l}$.)

The clinical and laboratory data are shown in Table 1.

It will be seen that there was significant improvement in several important parameters such as ESR and CRP, which are usually considered to indicate that a treatment is having a suppressive effect on the disease. This was supported by improvement in clinical activity of disease. These measurements also suggested deterioration in the patients' condition when the drug was withdrawn. The major adverse effect noted in the laboratory measurements was a rise in the liver function tests, but values began to return towards normal despite continuation of the phenytoin and in no case was the rise high enough to warrant discontinuation of therapy. There were no significant changes in haemoglobin (none of the patients was significantly anaemic at entry), white cell or platelet counts, or immunoglobulin levels.

\section{Discussion}

Drugs such as gold, penicillamine and immunosuppressive agents such as azathioprine and cyclophosphamide are undoubtedly effective in suppressing disease activity in patients with rheumatoid arthritis, but their usefulness is seriously limited by short term side effects such as myelotoxicity and renal impairment and long term concern about induction of malignancy with immunosuppression. Patients must be regularly monitored with blood and urine tests and often need to be brought to hospital by ambulance at regular intervals for this. This can add considerably to the cost of their treatment. If an alternative therapy could be found which was cheap, well established through long usage, had a known profile of side effects which were not generally harmful, and patients did not have to be monitored regularly with laboratory tests, this would be an advance. In addition, such a drug would have to be shown to be effective as a second line, disease modifying, slow acting agent.

We believe from the data acquired during this pilot study that phenytoin may be such a drug, and we are now comparing it in a double blind controlled trial with the standard second line drug penicillamine.

We would like to thank Dr G Volans of the New Cross Hospital Poisons Unit for the phenytoin measurements and Dr P O'Neill at Lewisham Hospital for the CRP measurements. This study was supported by Parke Davies Ltd.

Table 1 Measurements on patients in study

\begin{tabular}{|c|c|c|c|c|}
\hline \multirow[t]{2}{*}{ Measurement } & \multicolumn{4}{|l|}{ Time in study } \\
\hline & $\begin{array}{l}0 \text { Weeks } \\
(n=11)\end{array}$ & $\begin{array}{l}12 \text { Weeks } \\
(n=9)\end{array}$ & $\begin{array}{l}20 \text { Weeks } \\
(n=7)\end{array}$ & $\begin{array}{l}28 \text { Weeks } \\
(n=7)\end{array}$ \\
\hline RI (No) & $16(8-23)$ & $10(3-24)$ & $6(5-37)$ & $9(5-39)$ \\
\hline EMS (min) & $90(30-720)$ & $30(2-720)^{*}$ & $30(0-720)^{*}$ & $60(30-720)$ \\
\hline VAS (mm) & $38(2-73)$ & $20(5-75)$ & $8(3-16)^{*}$ & $9(5-40)$ \\
\hline $\operatorname{ESR}(\mathrm{mm} / 1 \mathrm{st} \mathrm{h})$ & $50(30-110)$ & $15(3-98)^{*}$ & $11(4-75)^{* *}$ & $30(10-79)^{*}$ \\
\hline CRP $(\mu \mathrm{g} / \mathrm{l})$ & $27(20-107)$ & $27(15-96)$ & $9(6-85)^{* *}$ & $23(12-82)^{* *}$ \\
\hline IgM RF $(\mu \mathrm{g} / \mathrm{l})$ & $560 \quad(430-729)$ & $456(402-520)$ & $216(168-339)^{*}$ & $563(428-683)$ \\
\hline Alk. phosphatase (IU/I) & $233(103-403)$ & $313(142-573)$ & $212(132-775)$ & $217(92-257)$ \\
\hline GGT $(\mu \mathrm{g} / \mathrm{l})$ & $18(7-120)$ & $79(12-271)^{* * *}$ & $49(13-363)$ & $16(10-25)$ \\
\hline
\end{tabular}

Measurements of Ritchie articular index (RI), duration of early morning stiffness (EMS), the visual analogue scale (VAS). ESR, CRP. IgM rheumatoid factor (IgM RF), alkaline phosphatase, and gammaglutamyl transferase (GGT) were made. Results are expressed as median (range) and are compared with the starting values by Wilcoxon's matched pairs signed rank test using 'Modistat' software. ${ }^{*} \mathrm{p}=0.05 ;{ }^{* *} \mathrm{p}=0.025 ;{ }^{* * *} \mathrm{p}=0.005$. 


\section{References}

1 Sorrell T C, Forbes I J, Burness F R, Rischbieth R H C. Depression of immunological function in patients treated with phenytoin. Lancet 1971; ii: 1233-5.

2 Dorsch H M, Jason J, Gelford E W. Transient antibody deficiency and abnormal $\mathrm{T}$ suppressor cells induced by phenytoin. N Engl J Med 1982; 306: 406-9.

3 Li P P, Willard D R, Goodman R, Vawter G. Malignant lymphoma after diphenylhydantoin therapy. Cancer 1975; 36: 1359-62.

4 Bauer E A, Cooper T W, Tucker D R, Esterly N B. Phenytoin therapy of recessive dystrophic epidermolysis bullosa. $N$ Engl J Med 1980; 303: 776-81.

5 Ebadi M S, Scott P M. Increase in collagen levels by diphenylhydantoin as a possible mechanism of drug-induced gingival hyperplasia. Clin Toxicol 1971; 4: 39-46.

6 Bobrove A M. Phenytoin in rheumatoid arthritis. Arthritis Rheum 1983; 26: 118-9. 